the possibilitios of this drug have been weighed. By its means alone some of these cases can be sustained in rclative comfort for year's; in other's, again, little influence can be detected. Personally, I have met with more difficully in giving a prognosis in this class of case than in any other. First and foremost, as a peg upon which to hang an opinion, should be an estimation of the digitalis effect-if this is good, that is an undoubtedly favourable element. Next, the type of case in which it is present. With mitral stenosis the course is usually worse than when associated with arterio-sclerosis, or when occurring in older patients. Iastly, the degree of cardiac enlargement, as estimated by percussion, offers some help, extension of dullness to the right of the sternum being an unfavourable sign. No single subjective symptom offers much aid, however, although, perhaps, the degree of dyspnoea is the most valuable index. A final reason of the uncertainty relating to the prognosis in auricular fibrillation rests in the fact that death may cnsue in such cases in two ways: There is the gradual failure, with all the signs of loss of compensation; there are also many instances of sudden death, the cause of which is in all probability to be attributed to ventricular fibrillation. Whilst the former casts its shadow before it, the latter does not, and remains an ever uncertain factor.

Parorysmal tachycardia, as the name implies, is an occasional and spontaneous incident wlose onset or dura. tion it is impossible to foretell. In these cases only general experiential evidence can help us. Such incidents are seldom fatal of themselves, but in some cases their incidence tends to be more frequent and somelimes more prolonged; this is a general tendency only. Such cases, however, are particularly liable to be incited by some reflex causc peculiar to the individual, such as gastro-intestinal disorders, and with treatment dirceted to these conditions a distinct check upon the paroxysms may be given, and, consequently, a more favourable prognosis can be offered.

Hcart-block of a degree sufficient to cause the typical Stolies-Adams syndrome must always be regarded as a scrious condition, despite the fact that some of these patients may live many years. Death may occur at any time, directly due to cessation of ventricular activity, an event which, like the fit to which it gires rise, cannot be foretold.

\section{Cardiac Dilatation.}

Next to the pulsus alternans, I consider that this condition is the most serious from the point of view of proguosis. It is, perhaps, less conclusively evidence of a fatal issue of the case than is alternation, but its onset is often more quickly followed by deatls. It is important to recognize what one means by this term "dilatation." It is cxhaustion of the property of tonicity, and loss of this function is just as much a definite incident as is, for example, loss of the power of contractility. Of the causes leading to this loss of tone we admittedly know practically nothing. Dilatation is certainly not necessarily the result of muscle failure or weakness; dilatation need not be regarded as a riatural accompaniment of failure of the heart's myocardium; rather might such failure be looked upon as the result of such loss of tone. A moment's consideration should show the truth of this relation. The post-mortem table shows us hearts whose muscle is well developed and healthy, and yet there is marked dilatation of all the chambers; conversely, advanced myocaidial disease may show not the least dilatation. Equally difficult is it to explain dilatation on the exhanstion theory from the clinical point of view, for there is every reason to believe that it may be of abrupt onset, occurring within a fow minntes or hours, and slowing none of the steadily progressive characters which we should expect if the myocardium was becoming weakened. For thesc reasons we regard dilatation as a definite possible incident which can arise in the course of a heart case. This condition is clinically characterized by three signs: (a) Quickened pulse-rate of regular rhythm; (b) extension of the area of cardiac dullness, especially to the right; and $(c)$ general signs of dropsies, etc. 'To be excluded from this sroup are those cases where dilatation may reasonably be the result of mechanical causes, such as that associated with empliysema or certain mitral cases. 'The quick pulse is uspecially significant. Its rate is maintained throughout, even when the patient is in bed and completely resting. Subjectiye symptoms may be remarkably few. Drugs fail to slow the pulse-rate; usually it progressirely accelcrates to the end. In some ways these cases resemble our type case; in them, too, alternation may oceur towards the end; anginal attacks may -oceur just before death, bit this is not the rule. Dilatation appears to occur indis criminately in all classes of hear't disease. T'here is, so far as I am aware, no sign which can indicate at the onset of the dilatation what the course is going to be. In younger people recovery nay follow, but it will bo slow, associated with a gradual slowing of the pulserate; recorery, when it occurs, can be very complete. In arterio-sclerosis the prognosis is almost hopeless; in mitral discase, too, the issue for long hangs in the balance, but certainly some cases recover.

\section{Angina Pectoris.}

Only to the severer type of this affection can we refer the slighter forms--the shooting pains at the heart's apex, the vague referred pains up into the heart or around the epigastrium-all these transient and frequent manifesta. tions, full of interest as they are,require no special note. Prognosis in angina has for years been regarded as rery grave, and with this mature opinion one would agref. That patients may die in an attack-may die, we presum: from the intense severity of the agony-has giren this dread condition an especial and peculiar prominence; but we do not think that this end is to be anticipated in all cases who suffer from this obscure but very real ill. Admitting as we do, however, its gravity, to what is ceath attributable in the remainder? We can suggest an answer for some, and this is that death is due to the same causes as those of the type case-namely, failure of contractility. Angina is met with especially in those cases which at one time or another have shown alternation; the clinical course of these cases often presents the same gradual but relentless downward trend which we have sucgested to be typical of myocardial exhaustion; and it is again met with in exactly the clinical lind of case in which alterna. tion is to be anticipated. Angina, then, owes its sombro prognostic significance not only to itself as an immediate lilling agency, but also to what its presence signifies.

\section{AN INVESTIGATION OF THE BEST METHODS OF DES'TROYING LICE AND OTHER BODY VERMIN.}

\author{
(A Preliminary Communication.)
}

By J. PARLANE KINLOCH, M.D.,

J.ECTURER IN PCBLIC HEALTH, CNIVERSITY OF ABERJEEN.

Tris investigation of the best methods of destroying lice was begun at the outbreak of the present war at a time when verminous conditions among soldiers werc especially difficult to control owing to the continual arrival of fresh recruits. In former times it was customary to regard such verminous conditions as a necessary consequence of the bringing together of large numbers of men, and vermin were regarded as sources of discomfort and irritation rather than as an actual danger. But in view of the present known relationship between vermin and the trans mission of disease, and in consideration of the prevalence of typhus in Serbia and elsewhere on the eastern front of the present war, it has seemed desirable to issne this pre liminary note on the results of the experiments so far made.

No previous worker has succeeded in lieeping lice alive and well apart from the human body. Murray, ${ }^{1}$ in his Economic Entomology, describes low the Dutchman Lecwenhoek, more than two hundred ycars ago, bred lice. Leewenhoek at first proposed to employ a poor boy as a fit subject for the experiment, but afterwards found that he could make the experinent with much more certainty on his own person, wearing for this purpose a special garter under which the lice were confined. In the present experiments it may be indicated that the laboratory boy proved equally disappointing, and that instead of a garter to confine the lice a finger-stall, while less artistic, liat many points in its favour. Even when the cxperiments were long continued the finger suffered only from a condition somewhat analogous to a mild treuch frost-bite as at present described. 
The work of Mr. Cecil Warburton ${ }^{2}$ on behalf of the Engish Local Government Board, in the investigation of rag flock as a possible distributor of vermin, is of interest. He succeeded after a great many experiments in breeding and rearing lice in a glaiss tube, which was lept close to the person night and day except when feeding was necessary, which was at least twice every twenty-four lours.

Early in the present experiments it became obvions that suitable and constant conditions for breeding and rearing lice must be secured before reliable results could be finally obtained. It has been found that in the incubator at body temperature and in the presence of the necessary amount of moisture lice can be bred and reared and kept alive for many days. The optimum temperature has still to be determined; it lies somewhere between $24^{\circ}$ C. $\left(75^{\circ}\right.$ F. $)$, and $37^{\circ}$ C. $\left(98^{\circ}\right.$ F. $)$, and the optimum humidity is dependent on the temperature. Previous observer's have apparently experienced difficulty in removing lice for feeding purposes. I have found no difficulty. When taken by a claw in a pair of fine flat pointed forceps and lifted up tenderly, the louse suffers no hurt. Much work remains to be done in investigating the best breeding and feeding conditions. Further, there is at the present time no accurate knowledge of the physiology of the louse, of its habits, of the manner in which it conveys infection from one person to another. Thus it is not clear whether the louse introduces the infection of typhus or relapsing fever in the act of feeding on its host, or whether it is by means of its faeces that infection is conveyed. So far, 1 have observed that defaecation constantly accompanies feeding. These problems will form the subject of a later report. It is obvious, then, that in the following report of the value of insecticides, the results may be subject to future correction when accurate knowledge of the biology of the lonse is available, and especially when constant conditions for breeding and rearing it liave been determined.

A great many substances have been recommended as a means of clestroying lice. In determining the values of such sulstances the experiments have to be repeated many times, and a great many lice have to bo used in cach experiment. Further, it is necessary to recognize that substances antagonistic to lice may possibly be rifferentiated into two great groups: One set of substances may have a true insecticidal or toxic value; the second group may have no direct or immediate insecticidal effect, but may, by their odour or otherwise, have a repellent effect on lice, and, if applied to the human body, may prevent them seeking such a body as a host. Both groups of substances may well have their place in the campaign against the louse.

\section{Immersion.}

As many substances recommended for the destruction of lice are fluids, it is of interest to observe the behaviour of lice under conditions of simple immersion. For this purpose 0.9 per cent. sodium chloride solution in water, it clear river water, and distilled water have been used in turn in a series of experiments, and it has beeu found possible in a few cases to revive the louse after immersion in the saline solution for sixty hours, in the river wate after forty-eight hours, and in distilled water after twelve hours. The structure and functions of the louse that permit a continuation of existence under such conditions are so far entirely uncietermined. In practice, and as was to be expected, frequent baths and frequent changes of clothing have been found to diminish greatly the prevalence of lice among troops, but these methods have failed to secure the $a b$ cnce of vermin.

\section{Heat.}

The influence of heat on vermin has iong been a subject of controversy. The attendants at institutions for cleansing verminous children, and laundrymen in general, have maintained that boiling failed to destroy lice. I naturally received such statements with a considerable degree of scepticism. In the present experiments it has been found that, contrary to experience with ordinary animals, dry lieat appears to be more destructive for lice than moist heat of equal temperature. 'Thus, it has been possible to revice lice after immersion for one minute in water at $100 \mathrm{C}$. Lice exposed to the same temperature for one minute in air never survive. Indeed, so far, neithor lice nor their eggs have been found capable of surviving exposure for half an hour to a dry heat of $65^{\circ} \mathrm{C}$. $\left(149^{\circ} \mathrm{F}\right.$.).

\section{Paraffin Bodies.}

The paraffin bodies have long had a reputation as insecticides. Using petrol for this purpose, it has so far been found impossible to revive the lice or to rear the eggs after immersion in petrol for one minute. Moreover, even the vapour of petrol is sufficient to kill within half an hour all lice and apparently all nits. The ordinary paraffin oils are less effective, but appear to kill lice by immersion for a few minutes. The colza oils have little effect, and the higher hydrocarbons, such as vaseline, have no real insecticidal value. So far as the present experiments have gono it would seem that the activity of the paraffin series decreases with increase of the specific gravity. There is, therefore, reason to believe that the insecticidal action of the lower paraffin; may depend on their greater diffusibility, and possibly also on their greater solvent power for some particular material of a fatty or waxy character in the cut:cle of the louse.

Petrol having been found to be the most active insecticide of the paraffin series, its practical application demands attention. The destruction of vermin in body clothing and bedding raises no difficulty. They may be cleansed in a petrol bath such as is employed in a dry cleaning apparatus.

But the application of petrol to the human body is another matter. Its volatile nature renders its insecticidal value transient, and former experience in cleansing verminous patients in hospitals has shown that there is a danger from fire, even when using less inflammable paraffins than petrol. I have accordingly made some experiments with the object of devising a safe petrol application. I have experimented with various solutions of petrol and soap in alcohol, and emulsions of petrol in water, but, so far, with little success. I have found, however, that a 1 in 4 solution of petrol in vaseline when rubbed on the skin kills lice when confined on the rubbed surface. This preparation is non-inflammable under working conditions. The large proportion of vaseline reduces the vapour pressure in the solution, and thus sufficient petrol is retained to excrt a destructive effect for some hours.

It has been shown that there is reason to beliere that the insecticidal action of the lower paraftins may depent on their diffusibility and solvent porver for fats, and in this connexion it is of interest to note the effect on lice of powerful fatty solvents other than the paraffins. I have found that benzene, toluene, and acetone are at least quite as lethal as petrol; they are, however, also very inflammable.

Chlorine Derivatives.

Certain chlorine derivatives of methane, ethane, and ethylene were next investigated, and these bodies required special consideration owing to their non-inflammable nature. I have found that chloroform and carbon tetra. chloride are very actively insecticidal, but in practice the irritant action of chloroform on the human skin and the unstable nature of the tetrachloride preclude their use.

The Castner-Kellner Alkali Company of Liverpool and the Weston Chemical Company of Runcorn kindly supplied me with samples of chlorine derivatives of cthane and ethylene and their products. For these tests I have used tetrachlorethane and pentachlorethane, and dichlorcthylene and trichlorethylene. $\Lambda$ s these solvents have only been made availabie during recent years, it seemed well to investigate briefly some of their general properties. I tested first the rapidity of their solvent action on lanoline and lard. I find that the chlorine derivatives of ethylene are more rapid in their action than those of ethane, and more rapid than any other of the fatty solvents I have used. To test their action on the skin, pieces of cottonwool soaked in the separate preparations were applied to the skin and covered with aluminium foil to prevent evaporation. The chlorine derivatives of ethylene are thus found to be definitely more irritant than those of ethane. Again, it was necessary to test the toxic effects of the vapours of these substances for animals other than lice. I find that they have a convulsive anaesthetic; action. 'Ten minutes' exposure to an atmosphere charged with these vapours induces convulsive morements and 
finally coma in an average sizenl guinea-pig; which revives if removed in time to fresh air. Rabbits confined for three hours in such an atmosphere show some respiratory irritation, but are not gravely affecterl. Man uncler similar conditions suffer's from headache and respiratory iliscomfort; these symptoms pass away on remuval to tiesh air.

I then tested the effect of the chlorine derivatires of ethane aud ethylene on lice. I find that they are more lethal to lice than any other substances I have uscel. Tmmersion in these chlorine derivatives immediately lestroys all lice and nits; and exposure to the vapou of these substances for five minutes is cqually. destructive. In these experimeuts dichlorethylene and triehlorethylene were found to be more active in this respect than tetrachlorethane and pentachlorethane, and it is intercsting to note that they have also a lower specific gravity and lower boiling point.

The chlorine derivatives of ethylenc and ethane cannot for economical reasons be applied like petrol and benzene in a dry cleaning process. The price of trichlorethylene and tetrachlorethane is at the present time $5 \mathrm{~s}$. a gallon, whereas petrol and beuzene are available at less than a quarter of that price. But in the form of soaps they are on the market as " Westropol," containing 25 per' ccnt. of trichlorethylene, and as "Westoran," containing 95 per cent. of tetrachlorethane, and I have found that inmersion for half an hour at $12^{\circ} \mathrm{C} .\left(54^{\circ} \mathrm{F}\right.$.) in a soap. solution containing 2 per cent. of trichlorethylene, or in an emulsion containing 10 per cent. of tetrachlorethane, appears to secure destruction of all lice and their eggs.

I hare found that a 1 in 4 solution of either dichlorethylene or trichlorethylene in vaseline. when rubbed on the skin kills lice when contined to the anointed surface, and that tinis action cndures for about twcinty four hours. 'There is on the market a preparation, "Vermin Westropol," that is said to act as a deterrent to rermin. It is stated to contain, in addition to the ingredients of ordinary "Westropol," a "special kind of heavy mineral oil fraction." The "Vermin Westropol" is rubbed into the skin, and allowed to act for at least ten minntes before it is washed off. A thin film of the "special kind of mineral oil fraction" remains on the skin after rinsing aud this is said to act as a deterrent to rermin. It is strauge that when the trichlorethylene is known to bo the active insecticide, a mineral oil inferior in this respect should be substituted for it, and however that may be, I find that the lungry louse fects on the human boly through the "heavy mineral oil fraction," and continues to live.

It is apparent that soap preparatious of trichlorethylene and of tetrachlorethane are among the safest and most efficient clcanser's of the human body infested by vermin and solutions of dichlorethylene and trichlorethylene in some such substance as vaseline, that allows their insecticidal action to be exerted for hours, act as deterrents to vermin. Further, when thus applied to the human slin, these preparations are only slightly irritant in thei action, aud their vapours have no toxic action on the liuman body.

\section{Phicnols.}

The germicidal value of the phenols has been well established by cxpcriment, but their insecticidal value, so far as I am aware, has not been proved and has been largely assumed, although they are in extensive employ nient, especially in laundries, as insecticides. Cyllin has been used in the present tests. It las been found that lice can be revived and their eggs can bo reared after inmersion for lralf an hour in a 5 per cent. emulsion of cyllin in water at $12^{\circ}$ to $15^{\circ} \mathrm{C}$. $\left(54^{\circ}\right.$ to $59^{\circ} \mathrm{F}$.). Iice and their eggs, howerer, appear to be destroyed after immersion for the same time in the same cmuls:on at $65 \mathrm{C}$. $\left(149^{\circ} \mathrm{F}\right.$.). in practice it has been my experience that it is not usually possible to depend on laundrymaids liceping phenol stecp-tanks at the required temperature. Immer'sion for tive minutes in even a 1 per cent. emulsion of cyllin at room temperature certainly stuns the lonse, and this fact may be of some practical value in the cleansing of rerminous people.

\section{Tolutile Oils.}

The volatile oils have alvays had a reputation as Testroser; of vermin, and there is cridence that some oils have an indircet value in this respect. For experi- mental purposes oil of peppermint containing the alcohol menthol, oil of cloves coutaining the phenol derivative eugenol, oil of cinnamon containing cinnamic aldehyde, oil of carraway with its ketone carvol, oil of wintergreen with its ester nethyl salicylate, and oil of turpentine with the terpenes as their main constituents, have been used. Other volatile oils, such as oil of eucalyptus, oil of thyme, oil of tansy, and oil of rue, have in turn been rocom.. mended as insecticides, and have been employed in these experiments. It has been found that over a moist vapour of any one of the volatile oils lice live for many liours at body temperature, aud after immersion for a minute in such oils the lice can be revired. The cxperiments hare. also shown that, if permitted, the louse greatly prefers free life and fresh air to confinement in an atmosphere impregnated with any of these substances. Further experiments are being instituted to determine to what extent the sevoral oils may discourage infestation of the liuman body by vermin.

\section{Other Substances.}

Many solid substances of widely varying nature and application have been adrocated as means of destroying lice. I have tested the effect of the emanations of ioclofor'm, camphor, and paraform, and find that over such sub stances, and in contact with them, lice live for many. hours at body temperatur:, and thereafter remain alive and well in the incubator. In garments dusted with borax, sulphur, and black hellebore, lice are found to go ou living. as also in clothing steeped in solntions of alum and salicin and then allowed to dry. It remains to be determined to what extent the presence of such sub. stances in clothing may indirectly discourage the invasion of Jice.

I have also made some experiments to ascertain the behaviour of lice towards the more common parasiticides. It was found that the hungry louse feeds and remains alive on the human body previously anointed with an ointment containing any of the following parasiticidesnamely, sulphur, balsam of Peru, storax, mercury oleate, chrysarobin, stavesacre, and black hellebore. Without doubt the louse prefers the clean body to the body thus anointed, but the same holds good with the clean forcarm and the arn anointed with lard.

\section{Conclusions.}

1. The louse can be bred and reared in the incubator under suitable conditions of temperature and moisture. Constant conditions for breeding and rearing lice in the incubator remain to be determined.

2. Dry heat is more effective than moist heat in destroying lice and their eggs. 'The louse can be revived after' immersion for one minute in water at $100^{\circ} \mathrm{C}$. Exposure to a dry heat at the same temperature and for the same time appears to kill both lice and nits.

3. The paraffin bodics are actively insecticidal, and of these petrol is the most effective. Lice and their eggs aro destroycd by immersion in petrol for one minutc, arrl they may be killed by exposure to the rapour of petrol for half an hour.

4. Powerful fatty solvents other than the paraffins ave actively insecticidal. Benzene, toluene, and acetone arc as toxic to lice as petrol. Certain chlorine derivatives of methane, ethane, and ethylene are more lethal to lice than any other substances, and have the important meat of being non-inflammable. Immersion in the chlorine derivatives of ethane and ethylene immediately destroys all lice and nits, and exposure to the vapour of these substances for five minutes is equally destructive. Even soap solu. tious containing 2 per ccnt. of trichlorethylene or 10 per ccut. of tetrachlorethane are capable of killing in half an honr at ordinary temperatures all lice and nits.

5. A 25 per cent. solution of dichloretliylene or trichlor. ethylene in raseline when applied to the human body has been found capable of exerting its insecticidal action for hours. The action of a 25 per cent. solution of petrol in vaseline is of shorter duration, but is also effective for some hour's.

6. The common phenol disinfectants in their usual degrees of dilution for disinfectant purposes and at ordinary tempcrature fail to kill lice or nits, even aftzi steeping for half an lour, but bccome efficient as insecticides if the temperature of the steeping-tank is maintained at $65^{\circ} \mathrm{C}$. 
7. The volatile oils hare no direct insecticidal effect. In a moist vapour of oil of wintergreen, oil of cloves, oil of caraw $y$, oil of turpentine, oil of eucalyptns, oil of thyme, etc., lice live for many hours at body temperature, and can be revived after immersion in these oils.

8. Over solid substances, such as iodoform, camphor, and paraform, and in contact with them, and in contact with garments impregnated with sulphur, borax, black hellebore, alum, etc., lice appear to remain practically unaffecteil.

9. 'The liungry louse feeds on the human body previously anointed with sulphur ointment, balsam of Peru, mercury oleate ointment, chrysarobin ointment, staves. acre ointment, and hellebore ointment. The louse car. tainly prefers the clean body, but it can feed on the body thus anointed and thereafter survive.

10. It has still to be determined whether some of these bodies that have been shown not to be actively insecticidal may not have, when rubbed on the body or placed in clothing, a useful repellent effect on body vermin.

\section{Practical Appicication.}

For practical purposes it has been found that destruc. tion of lice and nits is best secured by immersion of verminous garments and bedclothes in a petrol or benzene bath. Danger from fire and waste of petrol are avoided by using such a bath and extractor as are employed in a dry-cleaning apparatus. In such an apparatus 90 per cent. of the petrol or benzene is recovered for future use. A petrol or benzene bath is necessary, especially for uniforms and woollen garments generally. Where the clothing is such that it is not injured by immersion in water, steeping the garments for half an hour at $12^{\circ} \mathrm{C}$. $\left(54^{\circ}\right.$ F.) in a soap solution containing 2 per cent. of trichlorethylene or 10 per cent. of tetrachlorethane secures destruction of lice and nits. It is only fair to say that the only soap solutions that I have so far experimented with are those sold as "Westropol "and: Westoran." Steeping for half an hour in a 5 per cent. solution of cyllin in water maintained at $65^{\circ} \mathrm{C}$. $\left(149^{\circ} \mathrm{F}\right.$.) is also effective, and this temperature has no injurious shrinkage effect on woollen articles.

For economical reasons the chlorine derivatives of ethane and ethylene cannot at present be used in a dry cleaning process, but their soap preparations are of value. Petrol has a wide application and is readily obtained.

For cleansing the body itself bathing or sponging with soap solutions containing 2 per cent. of trichlorethylene or 10 per cent. tetrachlorethane gives the best results.

In view of the known insecticidal action of these chlorine derivatives of ethylene and ethane it is probable that good results would be obtained by shampooing verminous heads with their soap preparations, and it is also probable that a 25 per cent. solution of trichloretilylene in vaseline would form an efficient insecticidal pomade.

It is almost certain that lice world not continue to live on the human body if anointed daily with a 25 per cent. solution of trichlorethylene in vaseline, or on the body anointed twice daily with a solution of petrol in vaseline of similar strength. The odour of such an ointment is not unpleasant. But living under verminous conditions con. stant precautions would have to be taken and every method of destroying vermin would require to be employed.

Means for the destruction of lice are available. - Any attempt to render an army free from vermin in war time would require that all men occupying the same quarters at the same time, or for alternating short periods of time, would be regarded as a single unit for which a receiving station with cleansing apparatus would be provided. Such an attempt would also require that the movements of the men off duty were controlled. It would be limited by immediate military necessities.

There is reason to believe that vermin are responsible for the transmission of the infection of typhus fever, ${ }^{3}$ and Nicolle ${ }^{4}$ has shown that the louse can convey the infection. Epidemics of typhus fever come and go, and the amount of any epidemic will be influenced by the verminous conditions prevailing. In dealing with typhus patients vermin must first be destroyed by some of the methods above described. Ambulance men and receiving nurses are to be similarly protected, or, if arailable, a staff of ambulance men and receiving nurses alreaty immune by a previous attack of the disease are to be employed.

\section{REFERENCTS}

1 Murray: Economic Entomology. Aptera. Pages 395-396. South Kensington Museum Science Handbook. Chapman and Hall. 2 War burton: Reports on Rag Flock to the Local Government Board, 1910 1905. Pages 26-28. 4 Nicolle, Comte et Conseil: Compt. Rent, Acai. des Sci., 1909, cxlix, No. 10, p. 486 .

\section{THE WASSERMANN TEST :}

A Method not Necessitating the USE of Glinea-pigs AS THE SOURCE OF CoMplemen'T.

By OLIVER HEATH, M.A., M.B., B.C.Cantab., EMPORARY LIEUTENANT R A.M.C., AND ABSISTANT BACTERIOLOGIST IN THE DISTRICT LABORATORY, MILITARY HOSPITAL, GOLCHESTER.

When the writer came first face to face with the necessity of doing Wassermann tests two main difficulties appeared. First, it was found well-nigh impossible to learn the technique in default of personal instruction, and in the light of experience this appears to have been due to omission of details in many of the published descriptions, making it impossible to sit down and perform the test from the description. The second difficulty was the matter of extra space required and extra work entailed in housins and feeding guinea-pigs for the supply of complement. containing serum.

It is thought that these two hindrances, especially the latter, must be a source of trouble to workers in some other laboratories, possibly at the present time to some of those attached to military hospitals at home and abroad.

The first - and obvious - solution was to practise Fleming's modification, which is at once short, simple, and avoids the necessity of liceping guinea-pigs. But without entering into the discussion of the value of this "modification," one may perhaps say there are several valid reasons, well supported by recognized authorities, for preferring a method which includes the main principles of the original Wassermann method as now practised. These principles are :

1. Deviation of complement by syphilitic serums in the presence of antigen.

2. Inactivation of serums to be tested (and controls)

3. Use of added haemolytic amboceptor and complement in previously determined and sufficient quantities, the same always for every tube and every batch of tests.

The last two are not included in Fleming's test.

It is claimed for the technique described below that -

1. It does include the three main principles of the Wasser mann test as now practised, and is, in fact, a Wassermann test as opposed to a modification.

2. It avoids the use of guinea-pigs.

3. Comparatively small amounts of blood and materials are required, which means economy.

4. The time required is shortened to about 11 hours

5. The technique is efficient, and as simple as it can be mate, having full regard to efficiency, and has stood the test in practice during the past two years.

The most important of the points in which the techniquo differs from the original method is the use of fresh normal human serum for the supply of complement, in place of guinea-pig's serum, the amount of the complement present being titrated for each batch of tests and 2 units (minimum haemolytic doses $=$ m.h.d.) added to each tube, the serums tested having been inactivated. It is found in practico that serum cbtained regularly from the same person will usually contain the same amount of complement, probably 3 to 6 units in a volume. This amount appears to vary more on account of the greater or less ease with which different samples of sheep's corpuscles will haemolyze, rather than in different samples of serum from the same person tested against one sample of sheep's corpuscles. So far as the writer is aware, liuman complement is used for the Wassermann test in four "modifications" only, namely, those described by Stern, Hecht, Fleming, and d'Este Emery; but in none of these is the amrount estimated or regulated in any way, that present in each unheated serum to be tested being used; no attempt is made to have the same number of units for each serum to deviate. An objection may be urged on the ground that haemolytic amboceptor v. sleep's corpuscles is present in uncertain (and varying) amount in most human serums, and 